\title{
Surgical management of presbyopia
}

This article was published in the following Dove Press journal:

Clinical Ophthalmology

25 August 2012

Number of times this article has been viewed

\section{André AM Torricelli \\ Jackson B Junior \\ Marcony R Santhiago \\ Samir J Bechara}

Division of Ophthalmology, University of São Paulo Medical School, São Paulo, Brazil
Correspondence: André AM Torricelli 3300 Av Vereador Jose Diniz, conjunto 208, São Paulo, CEP 04604-006, Brazil Tel +55 II 55334900

Email andre_torri39@yahoo.com.br
Abstract: Presbyopia, the gradual loss of accommodation that becomes clinically significant during the fifth decade of life, is a physiologic inevitability. Different technologies are being pursued to achieve surgical correction of this disability; however, a number of limitations have prevented widespread acceptance of surgical presbyopia correction, such as optical and visual distortion, induced corneal ectasia, haze, anisometropy with monovision, regression of effect, decline in uncorrected distance vision, and the inherent risks with invasive techniques, limiting the development of an ideal solution. The correction of the presbyopia and the restoration of accommodation are considered the final frontier of refractive surgery. The purpose of this paper is to provide an update about current procedures available for presbyopia correction, their advantages, and disadvantages.

Keywords: presbyopia, surgical correction, treatment

\section{Introduction}

Presbyopia is the refractive ability condition when accommodative ability of the eye is insufficient for near vision. Presbyopia is age-related, usually starting to cause problems around the age of 40-45 years. ${ }^{1}$ In 2005 , the estimated global impact of presbyopia was 1.04 billion people, with over half of these not having adequate near-vision correction, and 410 million being listed as visually impaired (94\% in developing countries). ${ }^{2}$ Based on a cycle of spectacle replacement every 2-5 years, between 134 and 335 million spectacles would be required each year to meet this need. ${ }^{3,4}$ Presbyopia affects quality of life and was associated with substantial negative effects on health-related quality of life in a US population by McDonald et al..$^{5}$

The pathophysiology of presbyopia remains poorly understood. The theory of Helmholtz ${ }^{6}$ proposes that accommodation occurs as a result of the elastic properties of the lens and possibly the vitreous that allow the lens to round up and increase its power when zonular tension is relieved during ciliary muscle contraction. As the lens changes with age, the ability to round up and increase refractive power is lost. Sclerosis of the lens as the causative factor of presbyopia has been challenged in recent years by Schachar. ${ }^{7,8}$ The Schachar theory suggests that the longitudinal muscle fibers of the ciliary muscle contract during accommodation, placing more tension on the equatorial zonules while relaxing the anterior and posterior zonules. This force distribution causes an increase in the equatorial diameter of the lens, decreasing the peripheral volume while increasing the central volume. As the central volume increases, so does the power of the lens. Under this theory, presbyopia occurs because 
of the increasing equatorial diameter of the aging lens. Once the lens diameter reaches a critical size, usually during the fifth decade of life, the resting tension on the zonules is significantly reduced.

While it is well established that passive optical methods of treating presbyopia, such as monovision, multifocality, and bifocal or progressive addition lenses provide functional distance and near vision to presbyopes, these do not restore the active change in power of the eye that occurs during accommodation in the young eye. The optical factors that contribute to functional distance and near vision with multifocal intraocular lenses (IOLs), for example, are described as pseudoaccommodation because they provide functional near vision from a variety of nonaccommodative factors. Optical multifocality effectively increases the depth of field of the eye by increasing the range of distances in object space over which the eye cannot perceive a clear change in focus. Multifocal IOLs accomplish this with multiple simultaneous foci for different distances. This results in a compromise to the quality of the near and far images, resulting in a decrease in contrast sensitivity and acuity for all viewing distances. Other factors that can increase the depth of field of the eye include small pupils and optical aberrations, such as spherical aberration or astigmatism. While passive optical factors such as monovision, multifocality, bifocal or progressive addition lenses may be considered as appropriate methods for treating the symptoms of presbyopia, they are very different from restoring the true, dynamic dioptric change in power that occurs during accommodation in a young eye. ${ }^{1}$

Several technologies are being explored to achieve surgical correction of presbyopia. ${ }^{9-11}$ Despite these efforts, a number of limitations have prevented widespread acceptance of surgical correction of this disability. In fact, the correction of presbyopia and the restoration of accommodation remains a challenge. The purpose of this paper is to update the reader about some procedures available for presbyopia correction and to review the advantages and disadvantages of these several techniques.

\section{Current surgical attempts at presbyopia treatment}

In recent years, various surgical methods have been used in cataract and refractive surgery to treat presbyopia. However, none has emerged as the final solution for presbyopia. At present, presbyopia corneal procedures include monovision laser in situ keratomileusis (LASIK), photorefractive keratectomy (PRK), conductive keratoplasty (CK), presbyopic LASIK (presbyLASIK), and more recently, the IntraCor technique and the corneal inlay are being investigated. ${ }^{12}$ Presbyopic corrections can also be achieved through lens extraction. Besides, anterior ciliary sclerotomy is another procedure proposed for presbyopia treatment (Table 1).

\section{Monovision LASIK and PRK}

Patient age has been considered as an important variable affecting the outcomes of various corneal refractive producers, such as LASIK and PRK. ${ }^{13}$ Younger patients tend to have a more aggressive healing response, which may contribute to some regression of the effect of treatment. ${ }^{13}$ In LASIK, because of the decreased healing response, it is not clear whether age plays a significant role. Regardless of the healing process, LASIK correction can be problematic in presbyopic patients. Many presbyopic patients with myopia experience difficulties with near vision after their refractive error is corrected. Before surgery, many of these patients were able to read by taking off their eyeglasses; after surgery, they may feel frustrated by their decreased near/reading vision. Most patients choose to undergo refractive surgery to decrease their dependence on spectacles and are therefore not willing to wear reading glasses after surgery. ${ }^{14}$ Monovision has been used as a strategy to compensate for presbyopia by optically correcting one eye for distance vision and the other eye for near vision. ${ }^{15}$ However, this strategy induces anisometropia with a consequent reduction in binocular acuity and stereopsis. ${ }^{16}$ Success rates for monovision refractive laser correction range from $72 \%$ to $92.6 \% .{ }^{15-20}$ Factors related to better results include good interocular blur suppression posttreatment of anisometropia of less than 2.50 diopters (D), successful distance correction of the dominant eye, good stereoacuity, lack of esophoric shift, and the willingness and motivation to adapt to this visual system. ${ }^{16,21-24}$

Table I Surgical treatment of presbyopia

\section{Cornea}

Monovision

- Laser in situ keratomileusis

- Photorefractive keratectomy

Presbyopic LASIK (multifocal laser ablation)

Conductive keratoplasty

Intracor femtosecond laser

Corneal inlay

Lens

Monovision (monofocal IOL)

Multifocal IOL

Accommodative IOL

Sclera

Anterior ciliary sclerotomy

Abbreviations: LASIK, laser-assisted in situ keratomileusis; IOL, intraocular lens. 
Although older patients may be symptomatic from presbyopia and thus more willing to accept monovision, several studies ${ }^{16,22}$ have not shown any correlation between age and monovision success. Women selected monovision slightly more often than men did. ${ }^{16,17,24-26}$ The amount of monovision - binocular summation in which two eyes are used instead of one - is greatest when the difference in dioptric power (add) of less than $1.50 \mathrm{D}$ is used for the near eye. ${ }^{16,20}$ Higher add powers cause less interocular blur stability, decreased stereoacuity, and contrast sensitivity. ${ }^{16,23}$ The decision of what level of anisometropia to target remains controversial. Goldberg's study ${ }^{26}$ extended to $-2.50 \mathrm{D}$ for patients aged 65 years and older, whereas the study by Cox and Krueger had a maximum goal of $-2.00 \mathrm{D}^{27}$

Since certain limitations and complications still persist in excimer laser correction, it is imperative to proceed with a complete ophthalmologic examination, including visual acuity assessment, refraction, intraocular pressure, and fundoscopic examination, as well as corneal thickness and corneal topography assessment. Assessment of biomechanical properties of cornea may be helpful but it is still under investigation. Thin cornea and/or abnormalities on topography, such as keratoconus, may prevent the refractive error correction. Complications such as haze and postoperative pain in PRK, as well as complications regarding the flap, diffuse lamellar keratite, corneal ectasia and dry eye in LASIK correction may occur. LASIK and PRK for myopia and hyperopia have shown reasonable safety, efficacy, and predictability profiles in the presbyopic age group. ${ }^{14,28}$

\section{Presbyopic LASIK (multifocal laser ablation)}

The first intentional creation of a multifocal relation profile designed to correct myopic refractive error and maintain good uncorrected near vision was first attempted using PRK by Moreira et al. ${ }^{29}$ These authors suggested that the different strategies implemented to create a bifocal fit - in particular, the strategy to create a central steeper area resulted in a potentially safer and more consistent outcome. The use of LASIK as a more controllable technique for corneal multifocality, avoiding the plastic compensatory effect of the growing epithelium reactive to surface ablation profiles, seems to be more adequate for presbyopia correction. For the purpose of corneal multifocality, different presbyLASIK techniques have been proposed. In peripheral presbyLASIK, the central cornea is treated for distance, whereas in the periphery a negative asphericity is created to increase the depth of field. ${ }^{30}$ The relatively important amount of cornea tissue needed to be removed to create an intentional negative asphericity in myopic patients is the reason most of these procedures have been practiced and reported in hyperopic eyes. ${ }^{30}$ This method also requires an efficient excimer laser-beam profile capable of compensating for the loss of energy that happens while ablating the peripheral cornea; this is one of the main difficulties in targeting specifically high negative asphericity values with this technique. Authors involved in this investigation with different technologies are Telandro ${ }^{31}$ and Pinelli et al. ${ }^{32}$ In central presbyLASIK, a hyperpositive area is created for the near vision at the center, whereas the periphery is left for far vision. One distinctive advantage is that a central hyperpositive area can be performed at the center of the cornea with minimal corneal excision associated with myopic, hyperopic profiles and also in emmetropes. Both techniques are influence by luminance conditions; in fact, loss of best spectacle-corrected visual acuity (BSCVA) and decreased vision quality are the main concerns regarding presbyLASIK surgery. Alió et al, ${ }^{33}$ using central presbyLASIK, reported reduced contrast sensitivity at higher spatial frequencies, a finding probably related to change in corneal aberration in coma and the changes in the retinal point-spread function. Moreover, some patients had night halos and loss of two lines in distance BSCVA. Epstein and Gurgos,${ }^{34}$ using monocular peripheral presbyLASIK in hyperopic eyes, reported similar results.

Evidence from optic geometrical analysis of corneal surface suggests presbyopic correction up to $4 \mathrm{D}$ might preserve good quality of vision..$^{35}$ Most probably, presbyLASIK will offer a valid alternative for the correction of presbyopia, but scientific evidence is still necessary to support its widespread use today.

\section{Conductive keratoplasty}

$\mathrm{CK}$ is a nonablative, radiofrequency-based, collagenshrinking procedure that has been approved by the Food and Drug Administration for the temporary correction of mild to moderate spherical hyperopia ( $+0.75 \mathrm{D}$ to $+3.00 \mathrm{D})$ in people over the age of 40 years. ${ }^{36}$ Radiofrequency energy is delivered through a fine tip inserted into the peripheral corneal stroma in a ring pattern outside of the visual axis. When a series of eight to 32 treatment spots are placed in up to three rings in the corneal periphery (6-, 7-, and 8-mm optical zones), striae form between the spots and create a band of tightening, resulting in a steepening of the central cornea, correction of hyperopic refractive error and improvement in near vision. ${ }^{36}$ 
As a nonablative, nonincisional procedure that does not require creation of a flap and uses radio-frequency energy to steepen the central cornea, CK avoids LASIK-related complications. ${ }^{37} \mathrm{CK}$ can be performed in the office setting under topical anesthesia and involves the use of a portable unit that is much less expensive than most other refractive surgery platforms. After correction for near vision in one eye with CK, a phenomenon called "blended vision" has been observed. Different from monovision, in CK presbyopic correction appears to result in less compromise of distance vision binocularly, contrast sensitivity, or depth perception. ${ }^{36}$

A multicenter study by McDonald et al ${ }^{36}$ evaluated the safety and efficacy of CK for reducing the symptoms of presbyopia. Six months postoperatively, $77 \%$ of examined eyes had Jaeger 3 (J3) or better monocular near uncorrected visual acuity (NUCVA), and $85 \%$ of patients had binocular NUCVA of $20 / 25$ or better distance along with J3 or better near vision, a combination that represents functional acuity for a presbyope. In this study, accuracy to within $0.5 \mathrm{D}$ of target refraction was similar to that achieved in H-LASIK studies. These mostly showed accuracy to within $0.5 \mathrm{D}$ of $61 \%-79 \% .^{38-40}$

Significant regression of refractive and keratometric effects of CK has been observed over extended follow-up. Regression has been the main factor limiting the use of thermal keratoplasty treatments. ${ }^{37}$ Esquenazi et a ${ }^{41}$ report $26 \%$, $36 \%$, and $39 \%$ regression of refractive results at 4 weeks, 6 weeks, and 8 weeks, respectively, after CK treatment. Patients should be informed that this refractive procedure may not be permanent. ${ }^{42}$

Patient selection and education plays a vital role in CK surgery. Previous corneal surgery, epithelial or endothelial disease, keratoconus, pellucid degeneration, and significant dry eye are not considered good candidates. In conclusion, evidence suggests conductive keratoplasty acts as a temporary treatment of low to moderate hyperopia.

\section{Intracor femtosecond laser}

With the introduction of femtosecond laser technology in the field of corneal surgery, interest was stimulated in correcting refractive errors by applying femtosecond laser pulses to the corneal stroma without the need for cutting flaps or any other corneal incisions. In October 2007, the first treatments of presbyopia using the Technolas femtosecond laser (Technolas Perfect Vision, Munich, Germany) were performed by Luis Ruiz in Bogotá, Colombia. ${ }^{43}$ The Intracor procedure is performed using the Technolas femtosecond laser system, which delivers a completely intrastromal customized pattern of laser pulses into the cornea to induce a local reorganization of the biomechanical forces and change in corneal shape. The entire pattern of applied laser energy depends on the patient's refractive error, so that it not only improves NUCVA, but also corrects and improves uncorrected distance visual acuity in eyes with low ametropia. The basic pattern for presbyopia correction is a series of femto-disruptive cylindrical rings that are delivered within the posterior stroma, at a variable distance from Descemet's membrane, and extending anteriorly through the mid-stroma to an anterior location at a predetermined fixed distance beneath Bowman's layer. The pattern of laser delivery is entirely intrastromal, without impacting either the endothelium, Descemet's membrane, Bowman's layer, or epithelium at any point throughout the procedure. ${ }^{43}$ The net effect is a central steepening of the anterior corneal surface, not in the shape of a steep central island, but rather as a multifocal hyperprolate, corneal shape with an ideal, pupil-dependent aberration pattern.

The potential advantages of such a procedure are intrastromal delivery without breaking the epithelium, avoidance of pain and inflammation from the exposed ocular surface, speed of recovery due to the absence of surface wound healing, and stability of refractive outcome by preserving the strongest, anterior corneal fibers. However, whenever a new procedure is introduced, the potential disadvantages must also be considered and studied. These may include dissatisfaction with the hyperprolate aberration pattern, diffractive effects from the paracentral laser pulse delivery, high dependability on proper centration and alignment, and progression or loss of effect over time due to changes in the biomechanical corneal forces. ${ }^{43}$

In a study by Holzer et al ${ }^{44}$ with 25 presbyopic patients treated only in their nondominant eye, the majority gained several lines of near visual acuity. Some of the eyes showed only slight improvement in near visual acuity, which requires further investigation. Only $54.2 \%$ of patients treated achieved at least 20/25 distance visual acuity and were also able to read newsprint (equal to J3). The side effects seen to date are minimal, with a slight disturbance of visual acuity during the early postoperative hours due to the cavitation gas bubbles located in the cornea. The technique lacks the disadvantages of some other corneal refractive surgical techniques, with regard to postoperative pain, inflammation, haze, and biomechanical instability, due to the preservation of the corneal epithelium and anterior stromal fibers. Further studies with a larger number of eyes and longer follow-up are necessary to characterize this technology more fully. 


\section{Corneal inlay}

The AcuFocus corneal inlay (ACI 7000; AcuFocus, Irvine, CA) is currently being investigated in Food and Drug Administration clinical trials within and outside the US for the treatment of near-plano and plano presbyopia. The inlay received the Conformité Européenne mark for use in the European Union in 2005. This corneal inlay is designed to increase the depth of field using the principle of small-aperture optics to restore near and intermediate visual acuity without significantly affecting distance vision. ${ }^{12}$ The AcuFocus corneal inlay is a $10.0-\mathrm{mm}$ microperforated artificial aperture $(3.8 \mathrm{~mm}$ outer diameter; $1.6 \mathrm{~mm}$ inner diameter) made of polyvinylidene fluoride, a material reported to have high biocompatibility in vitro. ${ }^{45} \mathrm{~A}$ carbon pigment makes the inlay opaque. Sixteen hundred holes ( $25 \mathrm{~mm}$ diameter) arranged in a randomized pattern allow nutritional flow through the implant into the anterior stromal tissue to prevent corneal melting. Femtosecond laser is used to create a superior hinged flap in the nondominant eye. The intended depth from the corneal surface is $170 \mu \mathrm{m}$, and with the patient fixating on the excimer laser microscope's single light source, the corneal inlay is centered on the stromal bed, with the first Purkinje reflex in the center of the inner diameter of the inlay.

Seyeddain et al, ${ }^{12}$ in a study with patients' preoperative uncorrected near visual acuity between 20/40 (J5) and 20/100 (J10/11) in the surgical eye and NUCVA of at least 20/20 in both eyes, reported $97 \%$ patients (31 patients) could read J3 or better binocularly, including $72 \%$ (23 patients) who read $\mathrm{J} 1$ or better. During the 3-year follow-up, no inlay had to be explanted. Two inlays had to be repositioned 6 months after implantation because of initial misplacement seen on direct ophthalmoscopy. No patient had detectable central visual field defect, but there was a statistically significant decrease in the mean deviation (versus preoperatively) in the follow-up of surgical eyes. The thin aperture did not prevent fundus ophthalmoscopy examination.

One great advantage of the corneal inlay procedure is its potential reversibility because no ablation is performed over the optical axis, as in LASIK (presbyopic or monovision). Results indicate that this technique can also be safely performed in hyperopic or myopic presbyLASIK patients as a combined refractive procedure to correct ametropia and presbyopia. ${ }^{46}$ The inlay, however, like other refractive procedures, causes a small loss of contrast sensitivity. This loss of contrast sensitivity when tested with addition of glare (as a pupildependent function) under mesopic conditions was more pronounced when assessing the surgical eye only. Therefore, clinically relevant problems might occur predominantly under nighttime conditions. ${ }^{12}$

Although further studies and an even longer follow up would be helpful, the AcuFocus corneal inlay seems to be an effective and safe ${ }^{47}$ treatment for plano and near-plano presbyopia.

\section{Lens approaches}

As modern technology advances and expectations increase, cataract surgery is no longer purely a visual restoration procedure. The refractive component, including management of presbyopia, has become more important. At present, there is no single perfect solution for managing presbyopia. ${ }^{48}$ There are a few ways to compensate for the loss of accommodation with an intraocular lens. The accommodative IOL uses ciliary muscle contraction to change the dioptric power of the IOL. Another option is to provide the visual system with two simultaneous images, either monocularly using multifocal IOLs or binocularly through monovision. In monovision, one eye is optimized for distance vision and the other eye for near.

Current accommodative IOL approaches are based on the "focus shift" principle: through an essentially hypothetical mechanism, contraction of the ciliary muscle would move the optic anteriorly, thereby increasing the dioptric power of the eye. ${ }^{49} \mathrm{In}$ a review in $2007,{ }^{49}$ laser interferometry, which has a reproducibility of measurement of pseudophakic anterior chamber depth in the order of 3-4 $\mu \mathrm{m}$, was used to measure axial shift. ${ }^{50}$ Axial shift and thus true accommodative effect was small or even absent, and also very variable, making an individual prediction impracticable. Not surprisingly, distance-corrected near visual acuity (DCNVA) was not significantly better than that obtained with the monofocal IOL. No statistically significant correlation was found between axial shift and DCNVA. ${ }^{49}$ Patel et $\mathrm{a}^{51}$ reported no improvement of near uncorrected visual acuity with the AT-45 accommodative IOL. At this time, further studies are necessary for widespread accommodative IOL.

Multifocal IOLs use a refractive or diffractive technology that attempts to give patients a full range of vision (near, distance, and intermediate) and to increase their independence from glasses after surgery. Excellent clinical outcomes have been reported $;{ }^{52-55}$ however, patient dissatisfaction and secondary procedures, including IOL exchange, can also be significant. ${ }^{56-58}$ With the same purpose, monovision has long been used to provide near, intermediate, and distance vision and is one of the most common methods used in cataract patients to address presbyopia. ${ }^{59-62}$ Overall satisfaction with 
pseudophakic monovision has been approximately $80 \%$ or better. ${ }^{59,61}$ In a major review, ${ }^{59}$ the properties of multifocal IOLs were compared to monofocal IOLs. There was no difference between the two types of IOLs in best-corrected or uncorrected distance acuity; however, multifocal IOLs provided better uncorrected near acuity. Nevertheless, multifocal IOLs reduced contrast sensitivity and caused more glare and halos. These optical effects can be so disturbing that secondary intervention and IOL removal after the original surgery might be required. Leccisotti ${ }^{57}$ reported that of 52 patients planned for bilateral presbyopic surgery, eight cancelled the fellow-eye surgery because of halos from the implanted multifocal IOL. Leccisotti also reported that 18 eyes of twelve patients required secondary intervention (PRK) after the surgery. Zhang et al, ${ }^{48}$ in a study comparing bilateral diffractive multifocal IOL and monovision pseudophakia, reported the multifocal IOL group did better than the monovision group in all three distance-vision components, probably because the target in both eyes in the multifocal IOL group was plano, while only one eye in the monovision group was targeted for plano. However, there was no statistically significant difference in the three components between the two groups. Halo and glare, not visual acuity or spectacle independence per se, were often the main complaints of patients in the multifocal IOL group. Halo and glare symptoms with multifocal IOLs have been well described. ${ }^{52,56,63-65}$ In the same study, $77 \%(17 / 22)$ of monovision patients and $67 \%(14 / 21)$ of multifocal IOL patients reported never needing glasses for newspaper reading $(P=0.331)$, and multifocal IOL patients had better near vision but not better spectacle independence for newspaper reading. Finally, although the two groups had comparable spectacle independence for computer work without glasses (65\% in multifocal IOL group and $76 \%$ in monovision group; $P=0.675)$, more patients in the monovision group $(20 / 21 ; 95 \%)$ than in the multifocal IOL group $(14 / 19 ; 74 \%)$ reported having less difficulty using a computer without glasses $(P=0.048)$. This was probably related to the difference in intermediate vision between the two groups. In fact, patients implanted with a multifocal IOL with lower addition $(\mathrm{ReSTOR}+3.00 \mathrm{D})$ had better performance at intermediate distances compared with the ReSTOR +4.00 D add IOL with similar performance for distance and near visual acuity, contrast sensitivity, and quality of life. ${ }^{54,66}$

In conclusion, although bilateral multifocal IOL remains a good option for patients who desire good vision and spectacle independence, monovision can provide comparable good distance and near vision.

\section{Anterior ciliary sclerotomy}

First suggested by Spencer Thornton, anterior ciliary sclerotomy involves making radial incisions in the sclera overlying the ciliary muscle. ${ }^{7}$ Based on Schachar's theory, this may allow expansion of the sclera overlying the ciliary body, increasing the space between the lens equator and ciliary body. ${ }^{67}$ This may place more resting tension on the equatorial zonules, allowing for increased tension to develop during ciliary muscle contraction. The procedure is hypothesized to restore accommodative amplitude in presbyopic subjects. Fukasaku and Marron ${ }^{68}$ reported a good initial effect from anterior ciliary sclerotomy, with a mean increase in accommodative amplitude of 2.2 D. The effect of surgery gradually disappeared, with only 0.8 $\mathrm{D}$ of gain in accommodative amplitude remaining at 1 year postoperatively. The authors attributed the loss of effect to healing of the sclera and proposed placement of silicone plugs in the incisions to prevent scleral healing. They reported that the silicone plugs reduced this regression, yielding a mean accommodative amplitude gain of $1.5 \mathrm{D}$ at 12 months. Hamilton et $\mathrm{al}^{67}$ demonstrated in a prospective controlled study that anterior ciliary sclerotomy failed to produce a statistically significant improvement in either accommodative amplitude or near vision through best distance correction. An alternative technique for scleral expansion uses polymethyl methacrylate bands placed in tunneled partial-scleral thickness incisions overlying the ciliary body in each of the four quadrants. This technique is called scleral expansion segment surgery. One well-controlled study examined accommodative amplitude before and after scleral expansion segment surgery using a dynamic infrared optometer. ${ }^{69}$ There was no evidence of improved accommodative amplitude postoperatively. Besides, $\mathrm{He}$ et $\mathrm{al}^{70}$ demonstrated that ciliary muscle is preserved in presbyopes and is still capable of greater accommodative excursions with greater accommodative efforts without any kind of procedure.

Evidence suggests that anterior ciliary sclerotomy or any other scleral surgical technique is not an appropriate treatment for the correction of presbyopia. Better-controlled studies are needed before widespread adoption of these techniques.

\section{Conclusion}

After an extensive review of the techniques and results of treatments aimed at correcting both distance and near vision in the presbyopic population, we noted that a unique and ideal solution is still not available. In fact the search for the restoration of true accommodation remains a challenge. In most of the procedures, near vision is achieved at the expense 
of far vision and/or quality of image. Technological advancements in terms of surgical instruments, biomaterials, and engineering and surgical capabilities have certainly moved surgical restoration of accommodation from a theoretical concept more into real ophthalmic practice, but much work still remains. Another major point is that neuroadaptive responses in presbyopia have not been adequately studied. Understanding which patients have neuroadaptive abilities may aid in patient selection. The ophthalmologist should decide which surgical management is the best choice for each patient. The most important recommendation is to help patients to set realistic expectations, and together with the subject evaluation, predict the effectiveness of surgery.

\section{Disclosure}

The authors report no conflicts of interest in this work.

\section{References}

1. Evans BJ. Monovision: a review. Ophthalmic Physiol Opt. 2007;27(5): 417-439.

2. Holden BA, Fricke TR, Ho SM, et al. Global vision impairment due to uncorrected presbyopia. Arch Ophthalmol. 2008;126(12):1731-1739.

3. Brian G, du Toit R, Ramke J, Palagyi A. Monitoring and evaluation of refractive error and presbyopia for Vision 2020. Clin Experiment Ophthalmol. 2010;38(3):249-254; quiz 327-249.

4. Vincent JE, Pearce MG, Leasher J, Mladenovich D, Patel N. The rationale for shifting from a voluntary clinical approach to a public health approach in addressing refractive errors. Clin Exp Optom. 2007;90(6):429-433

5. McDonnell PJ, Lee P, Spritzer K, Lindblad AS, Hays RD. Associations of presbyopia with vision-targeted health-related quality of life. Arch Ophthalmol. 2003;121(11):1577-1581.

6. Glasser A, Kaufman PL. The mechanism of accommodation in primates. Ophthalmology. 1999;106(5):863-872.

7. Schachar RA. Cause and treatment of presbyopia with a method for increasing the amplitude of accommodation. Ann Ophthalmol. 1992;24(12):445-447, 452.

8. Chien $\mathrm{CH}$, Huang T, Schachar RA. A model for crystalline lens accommodation. Compr Ther. 2003;29(2-3):167-175.

9. Glasser A. Restoration of accommodation: surgical options for correction of presbyopia. Clin Exp Optom. 2008;91(3):279-295.

10. Dai GM. Optical surface optimization for the correction of presbyopia Appl Opt. 2006;45(17):4184-4195.

11. Ferraz CA, Allemann N, Chamon W. Phakic intraocular lens for presbyopia correction. Arq Bras Oftalmol. 2007;70(4):603-608. Portuguese.

12. Seyeddain O, Hohensinn M, Riha W, et al. Small-aperture corneal inlay for the correction of presbyopia: 3-year follow-up. J Cataract Refract Surg. 2011;38(1):35-45.

13. Loewenstein A, Lipshitz I, Levanon D, Ben-Sirah A, Lazar M. Influence of patient age on photorefractive keratectomy for myopia. J Refract Surg. 1997;13(1):23-26.

14. Ghanem RC, de la Cruz J, Tobaigy FM, Ang LP, Azar DT. LASIK in the presbyopic age group: safety, efficacy, and predictability in 40- to 69-year-old patients. Ophthalmology. 2007;114(7):1303-1310.

15. Farid M, Steinert RF. Patient selection for monovision laser refractive surgery. Curr Opin Ophthalmol. 2009;20(4):251-254.

16. Jain S, Arora I, Azar DT. Success of monovision in presbyopes: review of the literature and potential applications to refractive surgery. Surv Ophthalmol. 1996;40(6):491-499.
17. Wright KW, Guemes A, Kapadia MS, Wilson SE. Binocular function and patient satisfaction after monovision induced by myopic photorefractive keratectomy. J Cataract Refract Surg. 1999;25(2): 177-182.

18. Miranda D, Krueger RR. Monovision laser in situ keratomileusis for pre-presbyopic and presbyopic patients. J Refract Surg. 2004;20(4): 325-328.

19. Reilly CD, Lee WB, Alvarenga L, Caspar J, Garcia-Ferrer F, Mannis MJ. Surgical monovision and monovision reversal in LASIK. Cornea. 2006;25(2):136-138.

20. Johannsdottir KR, Stelmach LB. Monovision: a review of the scientific literature. Optom Vis Sci. 2001;78(9):646-651.

21. Westin E, Wick B, Harrist RB. Factors influencing success of monovision contact lens fitting: survey of contact lens diplomates. Optometry. 2000;71(12):757-763.

22. du Toit R, Ferreira JT, Nel ZJ. Visual and nonvisual variables implicated in monovision wear. Optom Vis Sci. 1998;75(2):119-125.

23. Sippel KC, Jain S, Azar DT. Monovision achieved with excimer laser refractive surgery. Int Ophthalmol Clin. 2001;41(2):91-101.

24. Goldberg DB. Comparison of myopes and hyperopes after laser in situ keratomileusis monovision. J Cataract Refract Surg. 2003;29(9): 1695-1701.

25. Braun EH, Lee J, Steinert RF. Monovision in LASIK. Ophthalmology. 2008;115(7):1196-1202.

26. Goldberg DB. Laser in situ keratomileusis monovision. J Cataract Refract Surg. 2001;27(9):1449-1455.

27. Cox CA, Krueger RR. Monovision with laser vision correction. Ophthalmol Clin North Am. 2006;19(1):71-75, vi.

28. Jain S, Ou R, Azar DT. Monovision outcomes in presbyopic individuals after refractive surgery. Ophthalmology. 2001;108(8):1430-1433.

29. Moreira H, Garbus JJ, Fasano A, Lee M, Clapham TN, McDonnell PJ. Multifocal corneal topographic changes with excimer laser photorefractive keratectomy. Arch Ophthalmol. 1992;110(7):994-999.

30. Alio JL, Amparo F, Ortiz D, Moreno L. Corneal multifocality with excimer laser for presbyopia correction. Curr Opin Ophthalmol. 2009;20(4):264-271.

31. Telandro A. Pseudo-accommodative cornea: a new concept for correction of presbyopia. J Refract Surg. 2004;20(Suppl 5):S714-S717.

32. Pinelli R, Ortiz D, Simonetto A, Bacchi C, Sala E, Alio JL. Correction of presbyopia in hyperopia with a center-distance, paracentralnear technique using the Technolas $217 \mathrm{z}$ platform. J Refract Surg. 2008;24(5):494-500.

33. Alió JL, Chaubard JJ, Caliz A, Sala E, Patel S. Correction of presbyopia by technovision central multifocal LASIK (presbyLASIK). J Refract Surg. 2006;22(5):453-460.

34. Epstein RL, Gurgos MA. Presbyopia treatment by monocular peripheral presbyLASIK. J Refract Surg. 2009;25(6):516-523.

35. Ortiz D, Alio JL, Illueca C, et al. Optical analysis of presbyLASIK treatment by a light propagation algorithm. J Refract Surg. 2007;23(1):39-44.

36. McDonald MB, Durrie D, Asbell P, Maloney R, Nichamin L. Treatment of presbyopia with conductive keratoplasty: six-month results of the 1-year United States FDA clinical trial. Cornea. 2004;23(7): 661-668.

37. Rojas MC, Manche EE. Comparison of videokeratographic functional optical zones in conductive keratoplasty and laser in situ keratomileusis for hyperopia. J Refract Surg. 2003;19(3):333-337.

38. McDonald MB, Hersh PS, Manche EE, Maloney RK, Davidorf J, Sabry M. Conductive keratoplasty for the correction of low to moderate hyperopia: US clinical trial 1-year results on 355 eyes. Ophthalmology. 2002;109(11):1978-1989; discussion 1989-1990.

39. Arbelaez MC, Knorz MC. Laser in situ keratomileusis for hyeropia and hyperopic astigmatism. J Refract Surg. 1999;15(4):406-414.

40. Lindstrom RL, Hardten DR, Houtman DM, et al. Six-month results of hyperopic and astigmatic LASIK in eyes with primary and secondary hyperopia. Trans Am Ophthalmol Soc. 1999;97:241-255; discussion 255-260. 
41. Esquenazi S, He J, Kim DB, Bazan NG, Bui V, Bazan HE. Woundhealing response and refractive regression after conductive keratoplasty. $J$ Cataract Refract Surg. 2006;32(3):480-486.

42. Ehrlich JS, Manche EE. Regression of effect over long-term follow-up of conductive keratoplasty to correct mild to moderate hyperopia. J Cataract Refract Surg. 2009;35(9):1591-1596.

43. Ruiz LA, Cepeda LM, Fuentes VC. Intrastromal correction of presbyopia using a femtosecond laser system. J Refract Surg. 2009;25(10):847-854.

44. Holzer MP, Mannsfeld A, Ehmer A, Auffarth GU. Early outcomes of INTRACOR femtosecond laser treatment for presbyopia. $J$ Refract Surg. 2009;25(10):855-861.

45. Dexl AK, Seyeddain O, Riha W, Hohensinn M, Hitzl W, Grabner G. Reading performance after implantation of a small-aperture corneal inlay for the surgical correction of presbyopia: two-year follow-up. J Cataract Refract Surg. 2011;37(3):525-531.

46. Yilmaz OF, Bayraktar S, Agca A, Yilmaz B, McDonald MB, van de Pol C. Intracorneal inlay for the surgical correction of presbyopia. J Cataract Refract Surg. 2008;34(11):1921-1927.

47. Santhiago MR, Barbosa FL, Agrawal V, Binder PS, Christie B, Wilson SE. Short-term cell death and inflammation after intracorneal inlay implantation in rabbits. J Refract Surg. 2012;28(2):144-149.

48. Zhang F, Sugar A, Jacobsen G, Collins M. Visual function and spectacle independence after cataract surgery: bilateral diffractive multifocal intraocular lenses versus monovision pseudophakia. J Cataract Refract Surg. 2011;37(5):853-858.

49. Menapace R, Findl O, Kriechbaum K, Leydolt-Koeppl C. Accommodating intraocular lenses: a critical review of present and future concepts. Graefes Arch Clin Exp Ophthalmol. 2007;245(4):473-489.

50. Findl O, Drexler W, Menapace R, Hitzenberger CK, Fercher AF. High precision biometry of pseudophakic eyes using partial coherence interferometry. J Cataract Refract Surg. 1998;24(8):1087-1093.

51. Patel S, Alio JL, Feinbaum C. Comparison of Acri. Smart multifocal IOL, crystalens AT-45 accommodative IOL, and Technovision presbyLASIK for correcting presbyopia. J Refract Surg. 2008;24(3):294-299.

52. Chiam PJ, Chan JH, Haider SI, Karia N, Kasaby H, Aggarwal RK. Functional vision with bilateral ReZoom and ReSTOR intraocular lenses 6 months after cataract surgery. J Cataract Refract Surg. 2007;33(12): 2057-2061.

53. Cionni RJ, Chang DF, Donnenfeld ED, Lane SS, McCulley JP, Solomon KD. Clinical outcomes and functional visual performance: comparison of the ReSTOR apodised diffractive intraocular lens to a monofocal control. Br J Ophthalmol. 2009;93(9):1215-1219.

54. Santhiago MR, Wilson SE, Netto MV, et al. Visual performance of an apodized diffractive multifocal intraocular lens with +3.00 -d addition: 1-year follow-up. J Refract Surg. 2011;27(12):899-906.
55. Santhiago MR, Netto MV, Espindola RF, et al. Comparison of reading performance after bilateral implantation of multifocal intraocular lenses with +3.00 or +4.00 diopter addition. J Cataract Refract Surg. 2010;36(11):1874-1879.

56. Woodward MA, Randleman JB, Stulting RD. Dissatisfaction after multifocal intraocular lens implantation. J Cataract Refract Surg. 2009;35(6):992-997.

57. Leccisotti A. Secondary procedures after presbyopic lens exchange. J Cataract Refract Surg. 2004;30(7):1461-1465.

58. Souza CE, Muccioli C, Soriano ES, et al. Visual performance of AcrySof ReSTOR apodized diffractive IOL: a prospective comparative trial. Am J Ophthalmol. 2006;141(5):827-832.

59. Finkelman YM, Ng JQ, Barrett GD. Patient satisfaction and visual function after pseudophakic monovision. J Cataract Refract Surg. 2009;35(6):998-1002.

60. Ito M, Shimizu K. Reading ability with pseudophakic monovision and with refractive multifocal intraocular lenses: comparative study. $J$ Cataract Refract Surg. 2009;35(9):1501-1504.

61. Greenbaum S. Monovision pseudophakia. J Cataract Refract Surg. 2002;28(8):1439-1443.

62. Ito M, Shimizu K, Amano R, Handa T. Assessment of visual performance in pseudophakic monovision. J Cataract Refract Surg. 2009;35(4):710-714.

63. Chiam PJ, Chan JH, Aggarwal RK, Kasaby S. ReSTOR intraocular lens implantation in cataract surgery: quality of vision. J Cataract Refract Surg. 2006;32(9):1459-1463.

64. Pieh S, Lackner B, Hanselmayer G, et al. Halo size under distance and near conditions in refractive multifocal intraocular lenses. $\mathrm{Br} J$ Ophthalmol. 2001;85(7):816-821.

65. Ortiz D, Alio JL, Bernabeu G, Pongo V. Optical performance of monofocal and multifocal intraocular lenses in the human eye. $J$ Cataract Refract Surg. 2008;34(5):755-762.

66. Sun Y, Zheng D, Song T, Liu Y. Visual function after bilateral implantation of apodized diffractive multifocal IOL with a +3.0 or $+4.0 \mathrm{D}$ addition. Ophthalmic Surg Lasers Imaging. 2011;42(4):302-307.

67. Hamilton DR, Davidorf JM, Maloney RK. Anterior ciliary sclerotomy for treatment of presbyopia: a prospective controlled study. Ophthalmology. 2002;109(11):1970-1976; discussion 1976-1977.

68. Fukasaku H, Marron JA. Anterior ciliary sclerotomy with silicone expansion plug implantation: effect on presbyopia and intraocular pressure. Int Ophthalmol Clin. 2001;41(2):133-141.

69. Mathews S. Scleral expansion surgery does not restore accommodation in human presbyopia. Ophthalmology. 1999;106(5):873-877.

70. He L, Donnelly WJ 3rd, Stevenson SB, Glasser A. Saccadic lens instability increases with accommodative stimulus in presbyopes. JVis. 2010;10(4):14.1-16.
Clinical Ophthalmology

\section{Publish your work in this journal}

Clinical Ophthalmology is an international, peer-reviewed journal covering all subspecialties within ophthalmology. Key topics include: Optometry; Visual science; Pharmacology and drug therapy in eye diseases; Basic Sciences; Primary and Secondary eye care; Patient Safety and Quality of Care Improvements. This journal is indexed on Submit your manuscript here: http://www.dovepress.com/clinical-ophthalmology-journal

\section{Dovepress}

PubMed Central and CAS, and is the official journal of The Society of Clinical Ophthalmology (SCO). The manuscript management system is completely online and includes a very quick and fair peer-review system, which is all easy to use. Visit http://www.dovepress.com/ testimonials.php to read real quotes from published authors. 